\title{
O EXPERIMENTO DIDÁTICO FORMATIVO E SUAS CONTRIBUIICÕES RELATIVAS AO PROCESSO DE APROPRIAÇÃO/OBJETIVAÇÃO DA ABORDAGEM DE QUESTÕES SOCIOCIENTIIFICAS POR PROFESSORES DE CIÊNCIAS
}

\author{
Wilka Karla Martins do Vale ${ }^{1}$ \\ Ruth do Nascimento Firme ${ }^{2}$
}

\begin{abstract}
RESUMO
Neste estudo temos os objetivos de analisar o desenvolvimento de um Experimento Didático Formativo (EDF) e identificar suas contribuições, na condição de método de investigação e método de ensino, relativas ao processo de apropriação/objetivação da Abordagem de Questões Sociocientíficas (AQSC) por professores de ciências. Os dados empíricos emergiram dos seguintes instrumentos: questionário, entrevista, observação e videogravação. Adotando a abordagem qualitativa dos dados, consideramos como categorias analíticas do EDF: a etapa do planejamento, a etapa de execução e a etapa de análises. A partir dos resultados das análises foi possível constatar que o EDF foi composto por etapas e subetapas coerentes com alguns pressupostos teóricos e metodológicos da teoria histórico-cultural, mais especificamente da teoria da atividade. Adicionalmente, algumas contribuições do EDF, relativas ao processo de apropriação/objetivação da AQSC por professores de ciências foram identificadas, como a subetapa de revisão bibliográfica acerca dos pressupostos teóricos e metodológicos da AQSC, objeto de apropriação/objetivação dos professores, e acerca dos pressupostos teóricos e metodológicos da teoria histórico-cultural, mais especificamente da teoria da atividade e do sistema de atividades. Isso porque tais revisões subsidiaram todo o processo do EDF, desde a etapa do planejamento até a etapa das análises.
\end{abstract}

Palavras-chave: Abordagem de QSC. Formação de professores de ciências. Teoria da atividade. Experimento didático formativo.

THE EDUCATIONAL EXPERIMENT AND ITS CONTRIBUTIONS RELATED TO THE PROCESS OF APPROPRIATION/OBJECTIVEIZATION OF THE APPROACH OF SOCIO SCIENTÍFIC ISSUES BY SCIENCE TEACHERS

\begin{abstract}
In this study we have the objectives of analyzing the development of a training educational experiment (TEE) and identifying its contributions, as a method of research and method of teaching, concerning the process of appropriation/objectiveization of the approach of Socio Scientific Issues (SSI) by science teachers. Empirical data emerged from the following instruments: questionnaire, interview, observation and video recording. Adopting the qualitative data approach, we consider as TEE analytical categories. The planning step, the execution step and the analysis step. From the results of the analysis, we can see that the TEE was composed of steps and substeps coherent with some theoretical and methodological assumptions of the historical-cultural theory, more specifically of the theory of activity. Additionally, some contributions from TEE, as a method of research and method of teaching, concerning the appropriation/objectiveization process of the approach of SSI by science teachers were identified, as the substeps of bibliographic review about the theoretical and methodological assumptions of SSI approach, objects of appropriation/objection of the teachers, and of the assumptions of the historical-cultural theory that gave allowances theorists and methodological to the research and the proposition of tasks that may have Required difficulties to be overcome by teachers.
\end{abstract}

Keywords: SSI approach. Training of science teachers. Theory of activity. Training educational experiment.

Recebido em: 8/8/2018

Aceito em: $2 / 7 / 2019$

Doutoranda pelo Programa de Pós-Graduação em Ensino de Ciências e Matemática da Universidade Federal de Pernambuco UFRPE. http://lattes.cnpq.br/9056444137196823. https://orcid.org/0000-0001-8083-6550.wilkiss_karla@hotmail.com

2 Doutora em Educação pela Universidade Federal de Pernambuco (2008-2012). Mestre em Ensino das Ciências pela Universidade Federal Rural de Pernambuco (2005-2007). Especialista em Docência no Ensino Superior pela Funeso (2003-2004). Graduada em Licenciatura em Ciências (Habilitação em Química) pela Universidade Federal Rural de Pernambuco. Professora-adjunta do Departamento de Química e da Pós-Graduação em Ensino das Ciências e Matemática da Universidade Federal Rural de Pernambuco. http://lattes.cnpq. br/7234636790850019. https://orcid.org/0000-0003-2737-5112. ruthquimica.ufrpe@gmail.com 
Neste estudo temos os objetivos de analisar o desenvolvimento de um Experimento Didático Formativo (EDF) e de identificar suas contribuições, como método de investigação e método de ensino, relativas ao processo de apropriação/objetivação da Abordagem de Questões Sociocientíficas (AQSC) por professores de ciências.

Segundo Ratcliffe e Grace (2003), as Questões Sociocientíficas (QSC) são aquelas que se alicerçam nas ciências; demandam constante posicionamento dos sujeitos; são controversas; envolvem diferentes dimensões, tanto políticas como científicas; repercutem na mídia e nos meios de comunicação em determinado período de tempo, ou seja, são transitórias, pois podem ser substituídas por outras questões emergentes da sociedade; e demandam discussões que envolvem o raciocínio moral e/ou o julgamento ético diante delas. Segundo Zeidler et al. (2005), as QSC, apresentam características como seu caráter midiático, a emergência da argumentação sociocientífica e o desenvolvimento do raciocínio moral. Nesse sentido, aquecimento global, nanotecnologia, consumo de água, melhoramento genético e alimentação, uso dos agrotóxicos, dengue e outras doenças infecciosas são considerados QSC, uma vez que podem gerar controvérsias, são temas midiáticos e para seu entendimento e discussão é necessário reconhecer aspectos relacionados com ciência, tecnologia, sociedade e ambiente.

Consideramos, portanto, que se faz uso de uma Abordagem de Questões Sociocientíficas (AQSC) no ensino de ciências quando se discute conceitos científicos articulados aos aspectos políticos, tecnológicos, econômicos, ambientais, éticos, etc., envolvidos em uma determinada QSC, e nesta perspectiva, incentiva-se a participação dos alunos por meio de diálogos, discussões e debates.

Na perspectiva de investigarmos o processo de assimilação de professores de ciências sobre a AQSC, assumimos pressupostos da teoria da atividade (LEONTIEV; LURIA; VIGOTSKY, 1991). Nesta direção, é recomendado que os conteúdos discutidos nos processos de formação docente sejam conduzidos de maneira estratégica, no sentido de oportunizar aos professores sua assimilação, na expectativa de contribuir para suas práxis pedagógica. Em outros termos, em um processo de formação docente, é desejável que os professores se apropriem de aspectos teóricos e metodológicos de propostas de inovação pedagógica, por exemplo, da AQSC, materializando-as em sua prática docente desde o planejamento didático até o processo de avaliação. Segundo Leontiev (2004), o homem se apropria de instrumentos e da cultura humana ao desenvolver atividades e, neste processo, se humaniza.

A apropriação é a internalização de conceituações decorrentes das atividades humanas e de suas condições histórico-sociais, entretanto esta se manifesta nos objetos ou fenômenos objetivados e, nesse sentido, não há apropriação sem objetivação (LEONTIEV, 2004). Dessa forma, quando ocorre a apropriação/objetivação da experiência histórico-social, segundo Leontiev (2004), ocorre a formação de novos modos de comportamento.

No contexto das pesquisas que têm como base pressupostos da teoria histórico-cultural, um método de investigação epistemologicamente coerente, por exemplo, para a pesquisa do processo de apropriação/objetivação, é o Experimento Didático Formativo (EDF), caracterizado "pela intervenção ativa do pesquisador nos processos mentais 
que ele estuda" (DAVIDOV citado por LIBÂNEO; FREITAS, 2013, p. 328). Nesta direção, no EDF é proposta uma reorganização dos conteúdos e de metodologias de ensino com vistas a propiciar um novo nível de desenvolvimento mental (DAVIDOV, 1988).

Considerando, portanto, as contribuições da AQSC para o ensino de ciências, a relevância de os professores assimilarem pressupostos desta abordagem em seus processos formativos, a pertinência da teoria da atividade e do EDF neste processo, e que o uso do EDF ainda não é recorrente nas pesquisas da área de ensino de ciências, conduzimos este estudo a partir da seguinte questão de pesquisa: Quais contribuições de um EDF, como método de investigação e método de ensino, relativas ao processo de apropriação/objetivação da AQSC por professores de ciências?

No sentido de obtermos respostas à questão de pesquisa delineada, discutiremos pressupostos teóricos e metodológicos da AQSC, da teoria de atividade e do experimento didático formativo.

\section{ABORDAGEM DE QUESTÕES SOCIOCIENTÍFICAS NO ENSINO DE CIÊNCIAS}

A Abordagem de Questões Sociocientíficas (AQSC) no ensino de ciências pode estimular os alunos a relacionarem suas experiências cotidianas aos conceitos científicos trabalhados na escola, despertar o interesse pelo ensino de ciências, estimular o debate, a argumentação e a verbalização em sala de aula, auxiliar no desenvolvimento do raciocínio dos alunos com maior exigência cognitiva e contribuir na aprendizagem do conhecimento científico e no entendimento da natureza da ciência (RATCLIFFE; GRACE, 2003; BORTOLETTO; CARVALHO, 2012).

Conrado e Nunes-Neto (2018) e Vale (2017), apontam que atualmente trabalhos com a AQSC objetivam: estimular a capacidade argumentativa dos estudantes em relação a temas específicos; entender o posicionamento dos alunos acerca de questões sociocientíficas; relacionar as efetivas contribuições de se discutir com professores como questões sociocientíficas contribuem para planejamento pedagógico; analisar o contexto social das controvérsias apresentadas em aulas de ciências; promover a interação entre alunos e professores ao discutirem problemas sociocientíficos.

Foi com esta perspectiva que lançamos nosso olhar para a AQSC na formação de professores de ciências. Isto porque, se por um lado esta abordagem, quando trabalhada nos processos formativos, é uma possibilidade para os professores investirem em ações que corroboram para inovar o seu repertório de estratégias didáticas e desenvolverem o pensamento crítico (CAPELO; PEDROSA, 2011), por outro, estudos sobre processos de formação docente para a AQSC ainda não são recorrentes.

Vale, Santos e Cunha (2016), por exemplo, realizaram uma revisão de literatura sobre a AQSC na formação de professores de ciências e identificaram estudos mais voltados para a investigação das concepções de professores sobre QSC e das possibilidades e dificuldades apontadas por eles para a inserção das QSCs na prática docente. Segundo Conrado e Nunes-Neto (2018), a maioria desses estudos não investiga processos formativos docentes para a AQSC. Para Capelo e Pedrosa (2011), contudo, as reflexões sobre o currículo de formação dos professores de ciências devem oportunizar a incorporação das QSCs em suas múltiplas dimensões. 


\section{TEORIA DA ATIVIDADE, APROPRIAÇÃO/OBJETIVAÇÃO, EXPERIMENTO DIDÁTICO FORMATIVO}

Segundo Leontiev, Luria e Vigotsky (1991), o desenvolvimento ocorre primeiramente pela atividade que o homem exerce de forma ativa e transformadora. Leontiev (2004, p. 315) designa por atividade "os processos que são psicologicamente determinados pelo fato de aquilo para que tendem no seu conjunto (o seu objeto) coincidir sempre com o elemento objetivo que incita o paciente a uma dada atividade, isto é, com o motivo".

Neste cenário, o processo de apropriação é a internalização de conceituações decorrentes das atividades humanas e de suas condições histórico-sociais (LEONTIEV; LURIA; VIGOTSKY, 1991). A apropriação não se resume à adaptação às conceituações e às significações de objetos, mas à internalização das significações historicamente formadas de modo criativo, articulando estas últimas às significações particulares na medida em que há uma reflexão sobre o uso de determinado instrumento (LEONTIEV; LURIA; VIGOTSKY, 1991). Não se trata de internalizar fielmente tais conceituações, mas de se apropriar de modo criativo, abrindo espaço para novas interpretações e conceituações. Segundo Leontiev, Luria e Vigotsky (1991, p. 180), portanto, a apropriação vai além da capacidade de mudança das qualidades dos indivíduos enquanto espécie, mas consiste na aquisição das conquistas de desenvolvimento da espécie ao tempo em que "ao satisfazer a necessidade de conhecimentos, o homem pode fazer de um conceito o seu conceito, isto é, apropriar-se da sua significação".

A objetivação, por sua vez, ocorre quando a atividade física e/ou mental dos homens transfere-se para o objeto dessa atividade (LEONTIEV; LURIA; VIGOTSKY, 1991). Neste sentido, segundo Moura, Sforni e Araujo (2011), os instrumentos, sejam mentais ou simbólicos, são mediadores entre o homem e a natureza, considerando que é por meio das significações historicamente objetivadas nos instrumentos, que o homem se transforma e transforma a função social desses instrumentos. O conhecimento acerca dos instrumentos materializados pela humanidade vai se transformando, na medida em que estes vão sendo encarnados de novas significações decorrentes das atividades desenvolvidas pelo homem, de acordo com a função do instrumento.

Ademais, a apropriação das aquisições das experiências histórico-sociais manifesta-se nos objetos ou fenômenos objetivados e a objetivação se constitui como condição essencial do processo de apropriação para a realização da transmissão destas aquisições para as gerações futuras. Não existe, portanto, apropriação sem objetivação e não existe objetivação sem apropriação. A apropriação e a objetivação são processos dialéticos, um não ocorre sem o outro, e a partir da relação dialética entre eles, motivo pelo qual adotamos neste estudo a expressão apropriação/objetivação, Leontiev estabeleceu características para o processo de apropriação: é sempre ativo, isto é, se constitui na realização da atividade com o instrumento (material ou simbólico) apropriado ou da atividade de produção do mesmo e se configura como mediador da formação social e individual dos sujeitos, e de igual modo, mediatizado pelas relações humanas (DUAR$T E, 2004)$. Desse modo, o indivíduo torna-se humano, apropriando-se dos resultados da história social e objetivando-se no interior desta história ao desenvolver atividades. 
Considerando que a atividade tem natureza coletiva e social, Engestrom (2006) propõe a atividade como um sistema, conforme Figura 1. Neste sentido, a atividade estrutura-se pelo sujeito em busca de transformar um objeto em um instrumento da sua comunidade.

Figura 1 - Estrutura do sistema da atividade

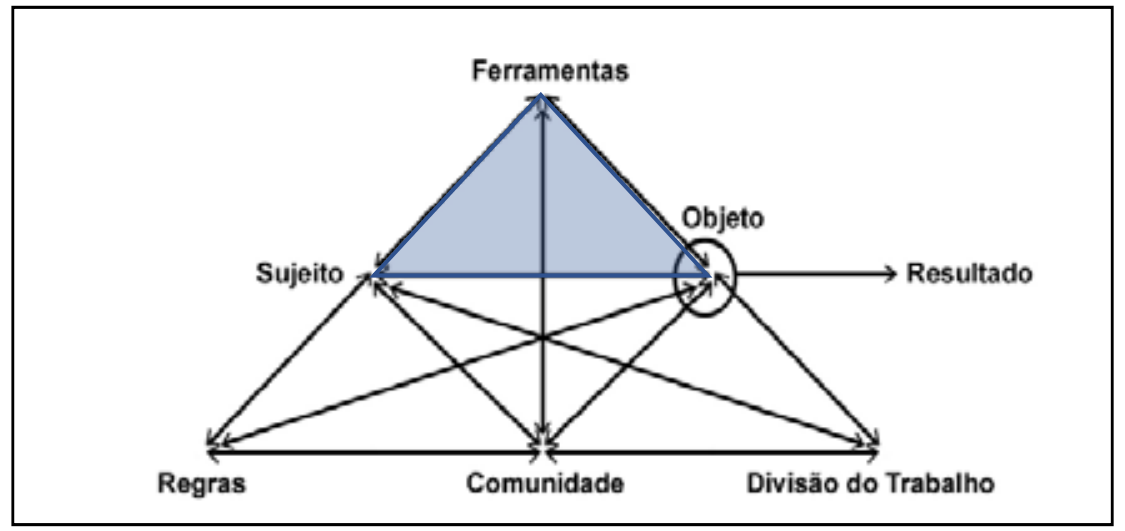

Fonte: ENGESTROM (2006).

Para Engestrom (2006), o sujeito ou o subgrupo é o cerne do sistema, pois sua atividade dirige-se para o objeto, representado pelo círculo, é moldado pelas ferramentas que dirigem a ação, explícita ou implicitamente, dependendo da transformação que precisa sofrer para atingir a necessidade para o qual foi destinado, ou seja, o resultado. O sujeito está inserido em uma comunidade (grupo de sujeitos) que compartilha um mesmo objeto, define regras que regulam as relações e as ações dos sujeitos que a constituem, e se relaciona com o objeto por meio da divisão de trabalho (ENGESTROM, 2006).

Leontiev, no entanto, considera que a atividade humana é um processo interno, regido e regulamentado pelo motivo do próprio homem e pela sua relação com o meio social. Por conseguinte, analisar os processos internos torna-se uma tarefa complexa considerando, por exemplo, que o processo apropriação/objetivação repercute no desenvolvimento mental dos sujeitos. Nesse contexto, o método denominado Experimento Didático Formativo (EDF) é considerado o mais adequado em estudos sobre o desenvolvimento da psique humana (AQUINO, 2014).

Segundo Davidov (1988), foi a partir da proposição de Vigotski, de que o desenvolvimento mental do homem se realiza quando este se apropria de modelos sociais por meio do processo de educação e de ensino, que ocorreu uma mudança na história da Psicologia. Nesta direção, o EDF foi inserido na investigação psicológica como um método de estudo das relações entre modos de educação e de ensino e a natureza do desenvolvimento mental (DAVIDOV, 1988). Assim sendo,

o método do experimento formativo tem como características a intervenção ativa do pesquisador nos processos mentais que ele estuda. [...]. A realização do experimento formativo pressupõe a projeção e modelação do conteúdo de novas formações mentais a serem constituídas, dos meios psicológicos e pedagógicos e das vias de sua formação (DAVIDOV, 1988, p. 188). 
Sendo uma das variantes do método genético-causal de estudo do desenvolvimento da psique dos indivíduos, o EDF é um método de investigação que consiste em estudar as mudanças no desenvolvimento do psiquismo a partir das ações efetuadas pelos sujeitos durante um processo de formação e/ou aquisição de conhecimentos (LIBÂNEO; FREITAS, 2007). Em outras palavras, "o pesquisador planeja atividades de ensino especialmente para fins da pesquisa, cuja intenção é intervir para colocar em movimento os processos que visa investigar" (SFORNI, 2015, p. 380-381).

Para Davidov (1988), o EDF propõe a organização e reorganização de novos programas escolares e de procedimentos didáticos que formem de modo ativo um novo nível de desenvolvimento mental. Neste sentido, de acordo com Aquino (2014), o EDF é simultaneamente método de investigação e método de ensino experimental que visa a potencializar a aprendizagem e o desenvolvimento dos estudantes no sentido intelectual, físico e emocional. Ainda segundo este autor, se aplicado adequadamente, "permite visualizar as tendências do desenvolvimento dos alunos, o trânsito entre as neoformações psicológicas e avaliar a dinâmica das relações socioeducativas do aluno" (p. 4.648$)$.

Zankov (1984) citado por Libâneo e Freitas (2013), desenvolveu estudos sobre o EDF. Para este autor, "a aplicação do experimento na investigação científica permite estudar as relações de determinadas facetas do processo e achar as causas que consolidam a necessidade do que apareça o fenômeno dado. [...]" (ZANKOV citado por LIBÂNEO; FREITAS, 2013, p. 240). Zankov elaborou princípios didáticos que orientam o EDF. São eles: o papel da formação dos conceitos científicos no desenvolvimento mental dos alunos; os métodos de ensino devem exigir dificuldades a serem superadas pelos alunos; a progressão dos alunos no estudo dos conteúdos escolares deve acontecer com celeridade, e a compreensão pelos alunos, por exemplo, da necessidade de aprender as causas do erro no processo de assimilação dos conteúdos.

Segundo Zankov (1984 citado por LIBÂNEO; FREITAS, 2013, p. 256):

O sistema dos quatro princípios didáticos tem seu campo de ação na exigência de que o professor dedique um quefazer sistemático e consequente para que todos os alunos da classe aprendam, incluídos os que têm dificuldades de aprendizagem.

Aquino (2014), por sua vez, propõe quatro etapas do EDF a serem realizadas pelo pesquisador/pesquisadora. São elas: 1) revisão da literatura e diagnóstico da realidade a ser estudada; 2) elaboração do EDF; 3), desenvolvimento do EDF e 4) análise e relatório de dados. As descrições destas etapas estão apresentadas no Quadro 1. 


\section{Quadro 1 - Etapas do EDF}

\begin{tabular}{|l|l|}
\hline $\begin{array}{l}\text { 1a etapa: Revisão da } \\
\text { literatura e diagnóstico } \\
\text { da realidade a ser } \\
\text { estudada }\end{array}$ & $\begin{array}{l}\text { Esta etapa é relativa à revisão bibliográfica acerca dos aspectos da teoria } \\
\text { histórico-cultural que serão adotados, visando à elaboração do quadro teórico } \\
\text { da pesquisa; ao diagnóstico da prática pedagógica realizada no contexto que } \\
\text { será desenvolvida a pesquisa e ao diagnóstico dos alunos com os quais se vai } \\
\text { trabalhar. }\end{array}$ \\
\hline $\begin{array}{l}\text { 2a etapa: Elaboração } \\
\text { do EDF }\end{array}$ & $\begin{array}{l}\text { Nesta etapa, ocorrem: } \\
\text { 1) a elaboração do EDF, preservando os conteúdos de ensino e submetendo- } \\
\text { os a uma nova organização didática. Nesta nova organização didática critérios } \\
\text { metodológicos devem ser considerados, como os objetivos devem refletir a } \\
\text { apropriação de conhecimentos, habilidades, etc., e a elaboração das tarefas } \\
\text { deve incluir a apropriação progressiva dos conceitos que serão trabalhados; } \\
\text { 2) a preparação dos professores para a aplicação do EDF. }\end{array}$ \\
\hline $\begin{array}{l}\text { 3a etapa: } \\
\text { Desenvolvimento do } \\
\text { EDF }\end{array}$ & $\begin{array}{l}\text { Nesta etapa, o EDF é aplicado. A técnica principal de coleta de dados é a } \\
\text { observação, e esta deve ser realizada por meio do registro filmado e gravado } \\
\text { e pela observação direta e sistemática do pesquisador. No final desta etapa } \\
\text { pode-se fazer uso de entrevistas individuais com os protagonistas do EDF, } \\
\text { bem como de avaliação escrita. Ainda nesta etapa ocorre a preparação dos } \\
\text { dados coletados para análise e pode-se aplicar entrevistas visando a entender } \\
\text { a partir das falas dos alunos, por exemplo, como ocorreu a apropriação do } \\
\text { método de aprender. }\end{array}$ \\
\hline $\begin{array}{l}\text { 4a etapa: Análise dos } \\
\text { dados e elaboração do } \\
\text { relatório }\end{array}$ & $\begin{array}{l}\text { Nesta etapa ocorre a análise dos dados, sendo orientada para os fatos } \\
\text { realmente observados, real, aposteriorística e que permita a elaboração de } \\
\text { conclusões do EDF. }\end{array}$ \\
\hline
\end{tabular}

Fonte: AQUINO (2014)

Adicionalmente, tendo como base os trabalhos de Vigotski, o EDF é utilizado em: estudos dos processos de trânsito da mente de uma formação psicológica e de aprendizagem para outra; estudos das condições de surgimento de fenômenos psíquicos e criação experimental das condições necessárias para que estes fenômenos surjam (DAVIDOV; MARKOVA, 1987).

À luz das discussões realizadas, portanto, e em busca de respostas à questão de pesquisa delineada, temos como objetivos neste estudo os de analisar o desenvolvimento de um Experimento Didático Formativo (EDF) e identificar contribuições, enquanto método de investigação e método de ensino, relativas ao processo de apropriação/objetivação da Abordagem de Questões Sociocientíficas (AQSC) por professores de ciências.

\section{METODOLOGIA}

Este estudo caracteriza-se como qualitativo, considerando que as pesquisas desta natureza valorizam a compreensão de significados que partem de um comportamento observado, permitem a adoção mais flexível de categorias de análise e consideram o pesquisador, sua experiência e suas atitudes, como parte integrante do levantamento e da análise dos dados (ALVEZ-MAZZOTI; GEWANDSZNAJDER, 1998).

Este trabalho é um recorte de uma pesquisa mais ampla desenvolvida com o objetivo de compreender como ocorre a apropriação e objetivação da Abordagem de QSC por professores de ciências, realizada no contexto da disciplina Perspectiva CTS e o En- 
sino de Ciências (PCTSEC) no segundo semestre letivo de 2016 do curso de Mestrado de uma Instituição de Ensino Superior (IES) brasileira, e contou com a participação de sete professores de ciências que cursavam esta disciplina. A disciplina em tela é ofertada anualmente no Programa de Pós-Graduação em Ciência e Matemática da IES e tem como ementa pressupostos teoricos e metodológicos da Perspectica CTS no ensino de ciências.

O EDF, foco de análise deste estudo, foi elaborado e constituído de etapas de planejamento, execução e análise, conforme Figura 2.

Figura 2 - Esquema com Etapas do EDF

\section{FASES DA PESQUISA}

\section{PLANEJAMENTO}

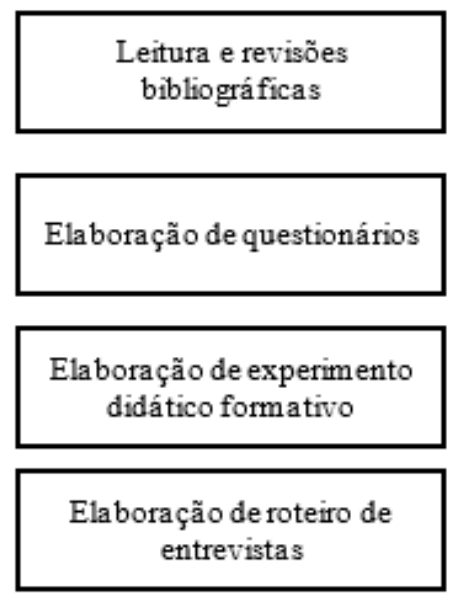

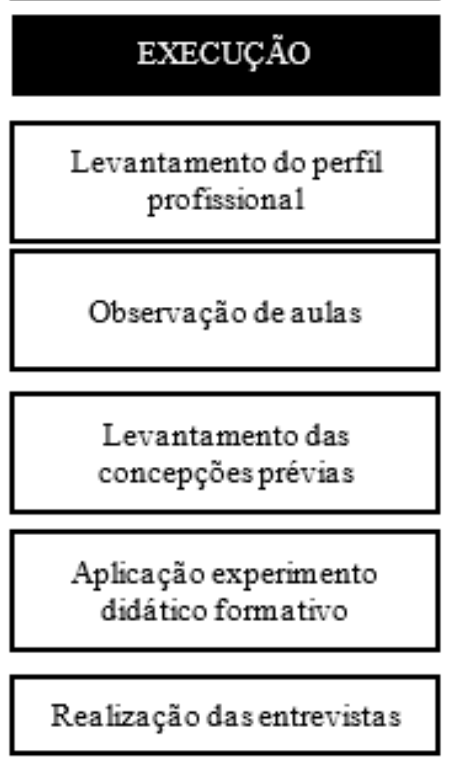

Fonte: Vale (2017).

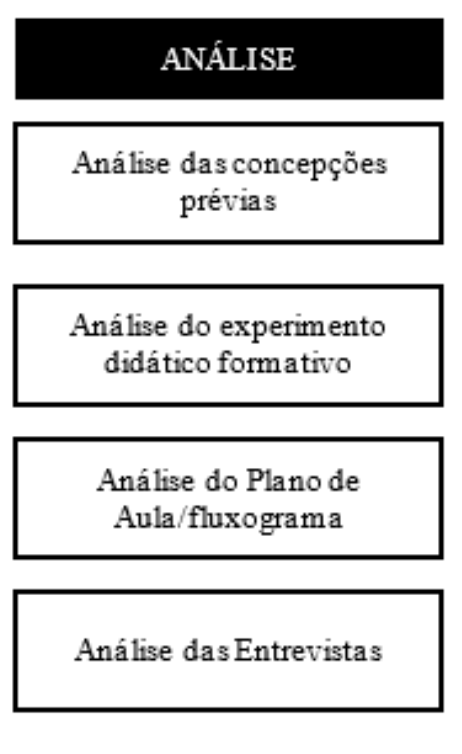

\section{ANÁLISE} prévias

álise do experiment didático formativo

Análise do Plano de Aula/fluxograma

Análise das Entrevistas

Os dados empíricos deste estudo foram coletados por meio de diferentes instrumentos, entre os quais: questionário, entrevista, observação e videogravação.

Para as análises dos dados empíricos coletados, as etapas e subetapas constitutivas do EDF se constituíram como categorias analíticas, conforme Quadro 2.

Quadro 2 - Relação das categorias e subcategorias analíticas

\begin{tabular}{|l|l|}
\hline \multicolumn{1}{|c|}{ Categorias analíticas } & \multicolumn{1}{c|}{ Subcategorias analíticas } \\
\hline Etapas do planejamento do EDF & $\begin{array}{l}\text { Leitura e revisão bibliográfica } \\
\text { Elaboração do questionário } \\
\text { Elaboração do EDF } \\
\text { Elaboração de roteiro de entrevista }\end{array}$ \\
\hline Etapa da execução do EDF & $\begin{array}{l}\text { Observação de aulas } \\
\text { Levantamento do perfil dos professores } \\
\text { Levantamento das concepções prévias } \\
\text { Aplicação do EDF } \\
\text { Realização das entrevistas }\end{array}$ \\
\hline $\begin{array}{l}\text { Etapa das análises dos dados } \\
\text { coletados no EDF }\end{array}$ & $\begin{array}{l}\text { Análises das concepções prévias dos professores } \\
\text { Análises da aplicação do EDF } \\
\text { Análises dos planos de aulas elaborados pelos professores } \\
\text { Análise das respostas dos professores às entrevistas individuais }\end{array}$ \\
\hline & Fonte: As autoras (2017). \\
& Contexto \& Educação \\
\hline
\end{tabular}




\section{RESULTADOS E DISCUSSÃO}

A discussão dos resultados deste estudo foi organizada considerando, inicialmente, as análises da primeira etapa do EDF, a etapa do planejamento, bem como subetapas deste momento - leitura e revisão bibliográfica, elaboração do questionário, do EDF e do roteiro de entrevista. Em seguida, ilustramos as análises da segunda etapa do EDF, a etapa de execução e suas respectivas subetapas - observação de aulas, levantamento do perfil dos professores, levantamento das concepções prévias, aplicação do EDF e realização das entrevistas. Finalmente, apresentamos as análises da terceira etapa do EDF, ou seja, as análises dos dados nele coletados relativos às concepções prévias dos professores, à aplicação do EDF, a um dos planos de aula construidos pelos professores e à entrevista final com estes professores.

\section{Análise do Planejamento do EDF}

A primeira categoria analítica do EDF refere-se à etapa do planejamento. A etapa do planejamento do EDF constituiu-se das subetapas de leitura e revisão bibliográfica, elaboração de questionários, elaboração do plano de ensino e elaboração de roteiro de entrevistas.

Inicialmente, destacamos que desde o início da pesquisa do Mestrado havia um interesse nosso em investigar a AQSC no contexto da formação de professores de ciências. Além disso, naquele momento, fazíamos parte do grupo de pesquisa ${ }^{3}$ que discutia pressupostos de Vigostski, da teoria da atividade de Leontiev e do sistema de atividades de Engestrom. Nesse sentido, a subetapa de leitura e revisão bibliográfica levou em consideração pressupostos: da AQSC; da teoria da atividade de Leontiev, mais especificamente dos conceitos de apropriação e objetivação, e do sistema de atividade de Engestrom. Como resultado da subetapa de leitura e revisão bibliográfica, definimos o objetivo da pesquisa - compreender como ocorre a apropriação e objetivação da Abordagem de QSC por professores de ciências - e o contexto de aplicação do EDF - a disciplina Perspectiva CTS e o Ensino de Ciências (PCTSEC), de um curso de Mestrado de uma IES brasileira. Nossa opção por esta disciplina considerou que nela são abordados pressupostos teóricos e metodológicos da perspectica CTS, e entre outros, a AQSC é um de seus conteúdos programáticos.

A subetapa seguinte foi relativa à elaboração do questionário do tipo aberto, considerado como instrumento viável para a garantia da uniformidade das questões, do anonimato, de menor custo e tempo empreendidos. Por meio do questionário, buscamos caracterizar o perfil dos sete professores matriculados na disciplina e que participariam, posteriormente, da aplicação do EDF.

Estas subetapas, portanto, corresponderam a dois dos três aspectos considerados por Aquino (2014) para a primeira etapa do EDF, ou seja, a revisão bibliográfica visando à elaboração do quadro teórico relativo aos pressupostos da teoria histórico-cultural que serão adotados na pesquisa e ao diagnóstico dos alunos com os quais vai se trabalhar.

O grupo de pesquisa conta com a participação de professores e alunos de Graduação e Pós-Graduação da IES. 
A elaboração do EDF correspondeu à terceira subetapa do planejamento. O EDF foi planejado considerando objetivos, conteúdos, metodologias, recursos didáticos e foi constituído por quatro principais tarefas: 1 ) discussão sobre aspectos teóricos e metodológicos da AQSC; 2) sistematização das características da AQSC em um fluxograma com previsão de ações pertinentes aos objetivos propostos por este tipo de abordagem; 3) desenvolvimento de roda de discussão sobre a temática intitulada "QSC para a promoção do letramento científico: possibilidades e limitações didáticas e pedagógicas", e 4) elaboração e apresentação de um plano de aula segundo a AQSC no ensino de ciências.

Todas as tarefas foram elaboradas na tentativa de contribuir para o processo de apropriação/objetivação da AQSC pelos professores de ciências, ao tempo em que se buscou uma nova organização didática para trabalhar os pressupostos teóricos e metodológicos desta abordagem, considerando a apropriação progressiva desses pressupostos, conforme proposto por Aquino (2014). Ainda destacamos que no EDF elaborado - Os conteúdos da disciplina (contexto da aplicação do EDF) - não foram alterados, visto que a AQSC fazia parte deles; houve uma busca da pesquisadora por objetivos correspondentes aos conteúdos e por métodos de ensino e recursos didáticos adequados aos objetivos e conteúdos; e os objetivos do EDF foram propostos para refletir na apropriação/objetivação da AQSC, por exemplo, o de reconhecer os objetivos desta abordagem e o de sistematizar suas características em um fluxograma com propostas de ações pertinentes aos objetivos da AQSC.

Todos estes aspectos convergem para as proposições de Aquino (2014) quanto à etapa de elaboração do EDF em relação a alguns de seus critérios metodológicos, por exemplo, busca pelos princípios gerais de organização sem alterar os conteúdos do programa vigente, e por objetivos que reflitam na apropriação da experiência humana, neste caso, na apropriação da AQSC. Adicionalmente, os objetivos e conteúdos propostos foram além dos princípios teóricos e metodológicos da AQSC, visto que um dos objetivos foi o de debater entre os professores possibilidades e limitações das QSCs para o ensino das ciências.

Destacamos, contudo, que na etapa de elaboração do EDF não houve a necessidade de preparação da professora da disciplina para a sua aplicação, visto que tanto a elaboração quanto o desenvolvimento do EDF foram conduzidos pela pesquisadora, uma das autoras desse trabalho.

Adicionalmente, no EDF elaborado, identificamos algumas convergências com os princípios propostos por Zankov (1984) citado por Libâneo e Freitas (2013), como foco nos aspectos conceituais relativos à AQSC em seus aspectos teóricos e metodológicos e tarefas (discussão sobre aspectos teóricos e metodológicos da Abordagem de QSC; sistematização das características da Abordagem de QSC em um fluxograma com previsão de ações pertinentes aos objetivos propostos por este tipo de abordagem; desenvolvimento de roda de discussão sobre "QSC para a promoção do letramento científico: possiblidades e limitações didáticas e pedagógicas", e elaboração e apresentação de plano de aula segundo a AQSC no ensino de ciências. Este conjunto de aspectos podem ter trazido aos professores dificuldades a serem superadas. 
Na subetapa elaboração de roteiro de entrevista, as questões foram elaboradas considerando que seria relevante ouvir os professores envolvidos quanto às suas percepções e expectativas acerca da vivência do EDF após sua aplicação. Isso porque, segundo Aquino (2014), as análises do EDF devem ser aposteriorísticas, ou seja, devem ser realizadas posteriormente à realização da experiência. Nesse sentido, a entrevista foi composta por quatro questões: Qual(quais) momento(s) vivenciado(s) no processo formativo você considera mais relevante(s) e que contribuiu(contribuíram) para que você assimilasse alguns dos pressupostos teóricos e metodológicos da AQSC no ensino das ciências?; O que você passou a entender sobre a AQSC?; Após a intervenção, o que você passou a considerar necessário para se utilizar a AQSC no ensino das ciências, justifique; Como você pretende utilizar conhecimentos sobre QSC na sua atividade docente?

\section{Análise da Execução do EDF}

A segunda categoria analítica do EDF refere-se à fase da execução. Na execução do EDF cinco subetapas podem ser destacadas: observação de aulas, levantamento do perfil dos professores, levantamento das concepções prévias, aplicação do EDF e realização das entrevistas. A subetapa de observação de aulas foi realizada durante seis semanas com duas horas de aula por semana, não houve interferência da pesquisadora nas aulas observadas e as anotações foram registradas em caderno de notas e por videogravação. É relevante mencionarmos que nesta subetapa o objetivo foi o de acompanhar o início da disciplina (contexto de aplicação do EDF) até o momento em que o próximo conteúdo fosse a AQSC. As aulas observadas referiram-se ao estudo de textos e seminários apresentados por duplas de professores sobre perspectivas sociológicas relacionadas à natureza da ciência. Na última aula observada, e antes de ser aplicado o EDF, a pesquisadora coletou informações sobre o perfil dos professores.

Embora a observação realizada não tenha se configurado com o mesmo objetivo da etapa de observação proposta por Aquino (2014), ou seja, observar a aplicação do EDF, esta parece ter sido relevante no processo, dado que aproximou a pesquisadora do contexto de aplicação do EDF. Além disso, esta subetapa contribuiu para um redesenho do EDF elaborado na etapa do planejamento e corroborou com ideias de Aquino (2014), ao tempo em que aspectos dos sujeitos e do contexto precisam ser identificados pelo pesquisador, podendo ser realizado por meio de um instrumento para o diagnóstico inicial.

No levantamento do perfil dos professores, subetapa seguinte, as respostas ao questionário sobre formação acadêmica, motivações para participar da disciplina e perspectivas como profissional docente, nos trouxeram algumas informações relevantes, tais como: os sete professores têm faixa etária entre 23 e 29 anos; cinco são licenciados em Biologia e dois em Química; obtiveram o título de licenciado entre os anos de 2012 e 2015; seis deles contavam com menos de dois anos de experiência docente e um com três anos. Os professores foram identificados por nomes fictícios, dos quais quatro homenagearam vítimas fatais do acidente radioativo de Goiânia com o Césio 134 em 1987 (Leide, Maria, Israel e Ivo), dois homenagearam a autora Raquel Carson e sua obra Primavera Silenciosa (Raquel e Primavera) e um homenageou vítimas da bomba de Hiroshima em 1945 (Hiroshima). Neste sentido, as questões foram elaboradas buscan- 
do, além do perfil desses professores, retomar de alguma forma seus motivos, suas necessidades, no sentido leontieviano do termo. Sobre os motivos, por exemplo, a maioria indicou que o que os levou a cursar o Mestrado foi a melhoria da profissão docente.

Quanto à subetapa relativa ao levantamento das concepções prévias, estas foram coletadas no primeiro dia da subetapa da aplicação do EDF. Para este levantamento foi solicitada aos professores uma redação sobre o tema "A abordagem de QSC nas aulas de ciências: perspectiva sobre possibilidades e limitações na prática docente". Sete redações foram escritas e os professores levaram em média 25 minutos para escrevê-las.

Ainda no primeiro dia da subetapa de aplicação do EDF, após o levantamento das concepções prévias dos professores, a pesquisadora ministrou uma aula expositiva e dialogada sobre a AQSC apresentando pressupostos teóricos e metodológicos postos na literatura, exemplos e o contexto de surgimento desta abordagem no ensino de ciências, e finalizou discutindo algumas de suas características. Ao final, a pesquisadora disponibilizou aos professores dois textos que tratavam da revisão de literatura acerca da relação entre a AQSC e a Perspectiva CTS.

No segundo dia da aplicação do EDF os professores realizaram duas tarefas: a construção do fluxograma e participação na roda de discussão. Minutos antes de os docentes iniciarem tais tarefas, a pesquisadora apresentou uma QSC sobre a substância fosfoetanolamina. Em seguida, apresentou vídeos sobre esta QSC e discutiu com os professores algumas relações entre a fosfoetanolamina e a cura do câncer. Na sequência, solicitou aos professores a elaboração do fluxograma. Para a realização desta tarefa a pesquisadora os organizou em dois grupos (grupo A e grupo B). Cada grupo foi composto de três integrantes, uma vez que a professora Raquel não pôde estar presente nesta aula. Os grupos foram orientados a construir um fluxograma que apresentasse possíveis estratégias didáticas para tratar a temática fosfoetanolamina como uma QSC. Destacamos que no momento da apresentação dos fluxogramas, espaços para as contribuições dos demais professores foram oportunizados.

Quanto à tarefa de participação na roda de discussão sobre o tema "Abordagem de QSC: Investigando estratégias didáticas e discutindo sobre as relações teóricas com a orientação CTS", esta foi dividida em quatro eixos: o que a abordagem de QSC considera por "letrar cientificamente os indivíduos"? (primeiro eixo); quais estratégias podem ser desenvolvidas em sala de aula em busca de promover o letramento científico e tecnológico? (segundo eixo); quais estratégias podem ser desenvolvidas em sala de aula em busca de promover o desenvolvimento moral e ético dos estudantes? (terceiro eixo); em que aspectos a abordagem de QSC contribui/se aproxima para a Orientação CTS? (quarto eixo).

No terceiro dia da aplicação do EDF os professores apresentaram os planos de aula, os quais foram elaborados individualmente em horário extraclasse. Estes foram apresentados em termos de objetivos, justificativas, temas e estratégias didáticas, com duração média de dez minutos cada. Após cada apresentação, a pesquisadora disponibilizou cinco minutos para perguntas e contribuições dos demais professores e da pesquisadora. 


\section{Análise dos Dados Coletados no EDF}

Finalmente, analisamos o EDF acerca da análise dos dados coletados. Esta etapa foi constituída de quatro subetapas: análise das concepções prévias dos professores; análise do EDF aplicado; análise dos produtos elaborados pelos professores e análise das entrevistas.

A análise das concepções prévias dos professores sobre a AQSC foi realizada a partir da leitura das redações escritas por eles, à luz da Análise Textual Discursiva constituída por três fases: desconstrução e unitarização; o processo de categorização e expressão das compreensões atingidas (MORAES, 2003). Neste sentido, o nosso primeiro movimento analítico foi desconstruir os textos buscando fragmentos mais relevantes, sentidos e significados neles presentes. Em seguida, categorizamos e identificamos impressões primeiras sobre a AQSC.

Como resultado desta análise podemos afirmar que os professores têm compreensões da AQSC como uma abordagem de ensino multidisciplinar, contextualizada, e que gera motivação para os alunos, mas não identificamos aspectos mais específicos que caracterizam a AQSC nas respostas dos professores. Trechos de três diferentes redações são evidências de compreensões dos professores, por exemplo, "Abordagem que pode mobilizar diversos saberes, não se resumindo a questões científicas" (Maria), "Traz para a sala de aula temáticas que envolvem aspectos científicos que são relacionados com o cotidiano do aluno" (Hiroshima) e "Questões de interesse da sociedade que promovem a formação de sujeitos críticos reflexivos e participativos quando tratadas em sala de aula" (Primavera). Ainda ressaltamos que a identificação das concepções prévias dos professores sobre a AQSC contribuiu para conduzir e/ou redesenhar outras tarefas propostas no EDF.

Outra subetapa analisada foi a aplicação do EDF com os professores. Nesta direção, utilizamos como categorias analíticas os componentes do sistema de atividades de Engestrom (2006), considerando que a identificação dos componentes que influenciaram as ações dos professores na execução das tarefas poderia ampliar as conclusões sobre o EDF desenvolvido.

Para ilustrar esta análise consideramos a execução da tarefa de construção de fluxograma pelos professores. Nesta direção os professores, sujeitos da atividade, construíram o fluxograma, o qual deveria apresentar estratégias didáticas possíveis para tratar a temática fosfoetanolamina como uma QSC. O objeto da tarefa eram estratégias didáticas para a AQSC. Na execução desta os docentes foram participativos, discutindo e questionando com a pesquisadora e entre eles. Os professores e a pesquisadora, portanto, constituíram a comunidade, pois compartilharam, neste momento, do mesmo objeto: estratégias didáticas para a AQSC. A execução da tarefa de construção de fluxograma foi mediada por regras e por uma divisão de trabalho. Os professores, por exemplo, deveriam elaborar os fluxogramas organizados em grupos, e a pesquisadora orientava os mesmos durante essa construção. Além disso, os próprios professores definiram regras em seus grupos. Por exemplo, um deles ficou responsável por apresentar o fluxograma construído. As regras e a divisão de trabalho são evidências das relações 
estabelecidas entre sujeitos da atividade (professores) e a comunidade. Adicionalmente, a execução desta tarefa pelos professores foi mediada por diferentes artefatos, por exemplo, as discussões estabelecidas na comunidade e os fluxogramas construídos.

A partir das ideias de Engestrom (2006), portanto, podemos afirmar que o EDF aplicado tem natureza social e coletiva e que na execução da tarefa de construção de fluxograma os professores buscaram transformar o objeto da tarefa, a AQSC, em um instrumento (fluxograma com estratégias didáticas para abordar a QSC relativa à fosfoetanolamina) para sua comunidade por meio de artefatos, regras e divisão de trabalho postas para eles e para a pesquisadora .

A partir da identificação dos elementos constitutivos da tarefa de construção do fluxograma e das relações estabelecidas entre eles, apresentamos uma representação do sistema de atividade, para este momento de desenvolvimento do EDF, segundo o modelo de Engestrom (2006), ilustrada na Figura 3.

Figura 3 - Sistema da atividade na execução da tarefa de construção de fluxograma

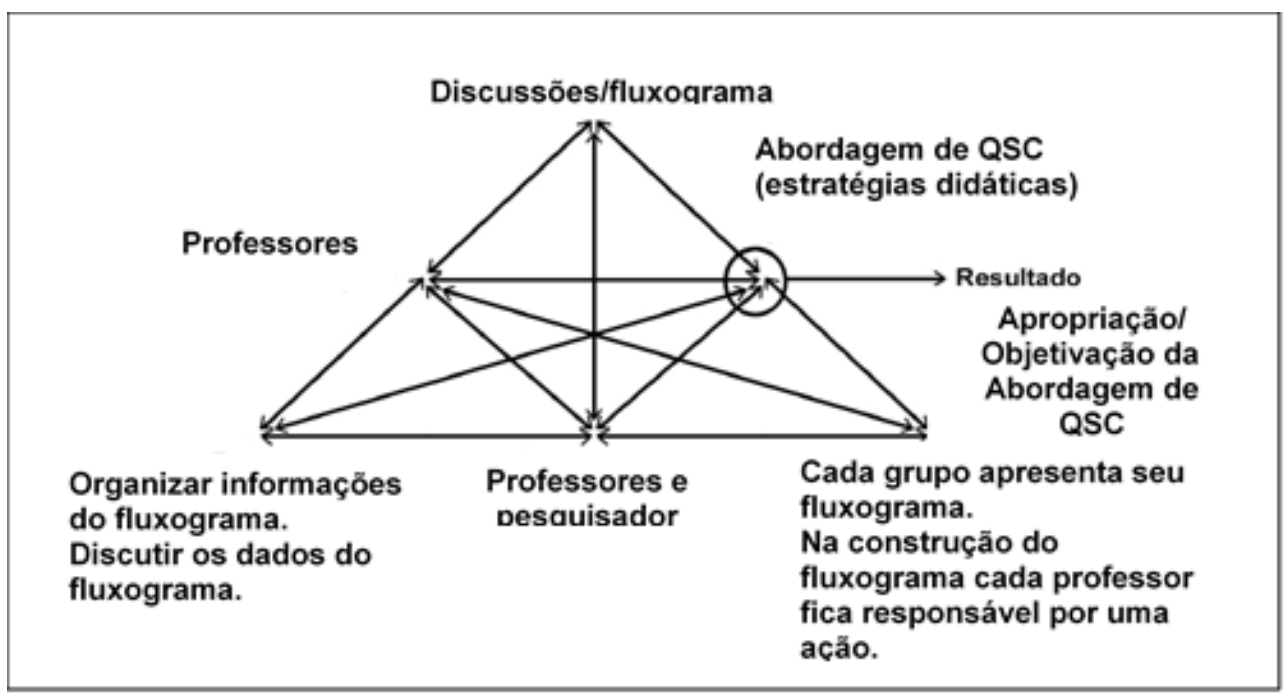

Fonte: Criação nossa.

Os planos de aulas elaborados pelos professores foram analisados considerando a temática proposta, as expectativas de aprendizagem, os conteúdos elencados e as estratégias didáticas previstas. Ilustramos esta análise com o plano de aula do professor Israel. O plano deste professor foi direcionado para a disciplina de Biologia e para o 30 ano do Ensino Médio, conforme trecho transcrito de sua fala no momento da apresentação do plano: "[...] observem que eu não coloquei aí essa questão de ácido nucleico porque isso é uma aula pra terceiro ano [...]". A temática proposta pelo professor Israel, "Biotecnologia: avanços e desafios", possibilita a abordagem de diferentes QSCs, por exemplo: impactos bioéticos, a clonagem humana, os alimentos transgênicos, controle embrionário, etc. Isso porque estas QSCs têm relevância social e podem suscitar discussões em suas dimensões sociais, ambientais, políticas, éticas, etc. Ressaltamos que QSCs envolvem controvérsias e podem, quando abordadas em sala de aula, promover a argumentação.

Outro aspecto identificado no plano de aulas do professor Israel refere-se à diversidade das expectativas de aprendizagem, ao tempo em que vão muito além da aprendizagem de conceitos científicos. Assim sendo, o atendimento às expectativas de 
aprendizagem para três aulas de 50 minutos talvez não seja garantido. E este aspecto é percebido pelo professor quando ele fala que: Eu só botei muitos [objetivos] porque como o tema ainda é abrangente... A biotecnologia... A gente trabalha com transgênicos... Com (inaudivel)... Trabalha tudo isso... Entende? E quando eu levo as notícias eu já levo recortada... Uma de genoma... Uma de clonagem... Uma de melhoramento genético vegetal outro animal... Entende? Pra ele ver como é abrangente esse tema... Por isso que eu tô esclarecendo". Quanto aos conteúdos, entendemos que eles contemplam aspectos científicos, tecnológicos, políticos, sociais, culturais, éticos, entre outros. São conteúdos que envolvem diferentes dimensões, como é de se esperar em uma AQSC. Em relação às estratégias didáticas propostas pelo professor Israel, consideramos que elas dão subsídios para a condução da AQSC, visto que foram previstas: a utilização de manchetes e notícias que trazem discussões sobre biotecnologia; aula expositiva sobre conceito e uso da biotecnologia; júri simulado que pode contribuir com o desenvolvimento da argumentação sociocientífica nos alunos e produção de texto pelos alunos como meio de socialização para a comunidade escolar. Em conjunto, os elementos propostos no plano de aula do professor Israel apresentam algumas características da AQSC, a saber: seu caráter midiático; o desenvolvimento de argumentação sociocientífica e desenvolvimento de raciocínio moral (ZEIDLER et al., 2005).

Finalmente, analisamos as respostas dos professores às entrevistas individuais, realizadas em etapa posterior à aplicação do EDF. Neste momento analítico o objetivo foi o de identificar compreensões dos professores de ciências sobre o processo do qual eles participaram, considerando, na visão deles, quais momentos contribuíram para a apropriação/objetivação da AQSC e sobre como eles passaram a compreender esta abordagem e como pode ser utilizada na prática docente. Vale destacar que desta etapa puderam participar apenas cinco dos professores - Israel, Ivo, Leide, Maria e Primavera.

Sobre a primeira questão da entrevista (Qual(quais) momento(s) vivenciado(s) no processo formativo você considera como mais relevante(s) e que contribuiu(contribuíram) para que você assimilasse alguns dos pressupostos teóricos e metodológicos da AQSC no ensino das ciências?), os professores apresentaram diferentes respostas. Israel e Primavera apontaram a elaboração do plano de aula e o professor Israel justificou dizendo que: "Eu acho que o plano de aula foi riquíssimo, saiu da teoria e vai pra prática". Os professores Israel e Maria sinalizaram a elaboração do fluxograma, e a professora Maria justificou dizendo que "Assim, pra mim todos os momentos foram importantes e trouxeram muita coisa sobre as questões sociocientíficas... mas eu acho que a parte que a gente fez o fluxograma foi um dos momentos mais ricos porque a gente já tinha discutido as aulas teóricas e lido alguns artigos sobre QSC". Os professores Israel e Leide mencionaram as aulas expositivas e dialogadas e a professora Leide destacou que: "Pra mim o momento da aula expositiva (e dialogada), que trouxe toda a história, todo o contexto do que seria uma questão sociocientífica, porque até então eu não conhecia com profundidade...." O professor Israel também justifica sua opção: "Aula expositiva e dialogada traz um aprofundamento teórico para consolidar sobre a abordagem de questões sociocientíficas". 
Para a segunda questão da entrevista ( $O$ que você passou a entender sobre a Abordagem de QSC?), as respostas da maioria dos professores nos leva a perceber que estes passaram a compreender aspectos característicos da AQSC, como seu caráter controverso e midiático e sua possível influência no desenvolvimento do cidadão com perfil ético e moral, como evidenciamos na fala do professor Ivo: "Percebi que essa abordagem busca colocar esse sujeito crítico em situações de embate a fim de que estes se posicionem tanto pelo empoderamento do discurso científico e tecnológico como pelas atitudes éticas e morais que permeiam o contexto em voga." Nesta fala, o professor Ivo enfatiza o posicionamento do sujeito crítico diante das situações controversas, considerando não apenas o discurso científico e tecnológico, mas atitudes éticas e morais.

Em relação à terceira questão da entrevista (Após a intervenção, quando fizemos a realização de certas tarefas, o que você passou a considerar necessário para se utilizar a abordagem de QSC no ensino das ciências? Justifique), os professores citaram o reconhecimento do resgate da história das ciências (professor Israel), as concepções prévias e a problematização (professora Primavera), a tomada decisão diante de um problema midiático (professor Ivo), o letramento científico para posicionamento crítico (professora Leide) e a participação pública (professora Maria), como aspectos que devem ser considerados para a instituição da AQSC.

E quanto à quarta questão da entrevista (Como você pretende utilizar os conhecimentos sobre QSC na sua atividade docente?), as respostas dos professores sinalizam diferentes maneiras, por exemplo, por meio da inserção mais efetiva da questão ambiental; de sequências de ensino/aprendizagem que desenvolvam a capacidade dos alunos de refletirem criticamente diante de questões sociais; de debates em sala de aula e propiciando a argumentação na sala de aula.

A partir das análises das entrevistas destacamos que o EDF aplicado com os professores propiciou resultados positivos quanto à apropriação/objetivação da AQSC por eles. Nesta perspectiva, podemos afirmar que, nas análises das respostas dos professores às questões da entrevista, identificamos "uma compreensão mais aprofundada sobre distintos aspectos observados nas aulas experimentais [...]" (AQUINO, 2014, p. 4.652 ). Adicionalmente, as entrevistas se constituem como instrumento de avaliação da fase final do EDF, conforme propõe Aquino (2014).

A nosso ver, as análises dos dados coletados na aplicação do EDF foram favorecidas pela observação da pesquisadora, por via direta, quando observou as aulas da disciplina antes da aplicação do EDF, e por meio da videogravação quando conduzia a aplicação do EDF. As análises, portanto, foram, de acordo com Aquino (2014), realizadas sobre aspectos realmente observados. Assim, a etapa de análises do EDF está coerente com as proposições de Aquino (2014), visto que, segundo este autor, um aspecto importante nesta etapa é o movimento que parte da observação dos fatos, passa pela abstração do essencial e conduz à generalização, permitindo a elaboração das conclusões acerca do EDF (AQUINO, 2014). 


\section{Contribuições do EDF para o Processo de Apropriação/Objetivação da AQSC}

A partir das análises das etapas do EDF (etapas do planejamento, da execução e de análise) identificamos contribuições do EDF, como método de investigação e método de ensino, relativas ao processo de apropriação/objetivação da AQSC pelos professores de ciências.

As análises da etapa do planejamento sinalizaram algumas contribuições, tais como: 1) a revisão bibliográfica sobre pressupostos teóricos e metodológicos da AQSC e sobre pressupostos da teoria histórico-cultural forneceu subídios teóricos e metodológicos ao desenvolvimento da pesquisa; 2) a delimitação do objetivo e do contexto da pesquisa refletiram no planejamento, na execução e na análise do EDF e 3) a elaboração do EDF. Neste sentido, a partir da delimitação do objetivo e do contexto da pesquisa, a pesquisadora buscou, no planejamento e na execução do EDF, "colocar em movimento os processos que visa investigar" (SFORNI, 2015, p. 380-381).

Considerando as análises da etapa da execução, outras contribuições podem ser destacadas, por exemplo: 1) a observação das aulas da disciplina e o levantamento do perfil dos professores foram etapas metodológicas que contribuíram para aproximar a pesquisadora do contexto no qual o EDF foi aplicado; 2) o levantamento das concepções prévias dos professores sobre a AQSC teve sua contribuição à medida que conduziu e/ou orientou o redesenho do EDF elaborado, na etapa de seu planejamento; 3) a aula expositiva e dialogada sobre pressupostos teóricos e metodológicos da AQSC, ministrada pela pesquisadora, conforme sinalizado na entrevista pelos professores Israel e Leide, como momentos relevantes, e 4) a tarefa de construção do fluxograma, visto que, segundo Leontiev citado por Duarte (2004), o processo de apropriação é ativo e se constitui na realização da atividade com o instrumento apropriado e da atividade de produção do instrumento, como foi o caso dos professores na execução da tarefa de construção de fluxograma.

Por fim, a etapa das análises dos dados emergentes da aplicação do EDF aponta algumas contribuições, tais como: quando analisamos os produtos elaborados pelos professores (fluxogramas e planos de aulas) e as percepções dos sujeitos acerca do que vivenciaram no EDF, pudemos elaborar inferências acerca do EDF. Entre outras, destacamos que, a partir das análises das falas dos professores ao responderem às entrevistas, podemos destacar que o EDF planejado, executado e analisado contribuiu para o processo de apropriação/objetivação da AQSC pelos professores de ciências. Isso porque a apropriação das experiências histórico-sociais manifesta-se nos objetos e a objetivação constitui-se como condição essencial do processo de apropriação para transmissão destas experiências para as gerações futuras (LEONTIEV; LURIA; VIGOTSKY, 1991).

Em síntese, podemos concluir que as análises, em conjunto, sinalizaram, do ponto de vista do método de investigação, que o EDF teve algumas convergências com as etapas propostas por Aquino (2014), e do ponto de vista do método de ensino, que o EDF propiciou aos professores de ciências novos olhares e novas significações para a AQSC.

\section{CONSIDERAÇÕES FINAIS}

As contribuições da AQSC para o ensino de ciências, a relevância de os professores assimilarem esta abordagem por meio de processos formativos, a pertinência da teoria da atividade e do EDF e o fato de que o uso do EDF ainda não é recorrente nas 
pesquisas da área de ensino de ciências, foram pressupostos assumidos neste estudo. Nesta direção, tivemos como objetivos analisar o desenvolvimento de um Experimento Didático Formativo (EDF) e identificar suas contribuições, como método de investigação e método de ensino experimental, relativas ao processo de apropriação/objetivação da AQSC por professores de ciências.

No atendimento aos objetivos delineados, analisamos as etapas de planejamento, de execução e de análise do EDF desenvolvido. As análises das respectivas etapas mostram que o EDF propiciou contribuições relativas ao processo de apropriação/objetivação da AQSC por professores de ciências, tais como revisão bibliográfica acerca dos pressupostos teóricos e metodológicos da AQSC, objeto de apropriação/objetivação dos professores e acerca dos pressupostos teóricos e metdológicos da teoria histórico-cultural, mais especificamente da teoria da atividade e do sistema de atividades. Isso porque tais revisões subsidiaram todo o processo do EDF, desde a etapa do planejamento até a fase das análises.

A partir desses resultados percebemos que o desenvolvimento de EDF é um caminho promissor para o pesquisador da área de ensino de ciências que busca compreender relações entre metodologias de ensino de ciências e o desenvolvimento integral dos alunos. Parece-nos necessário, contudo, aprofundar os estudos sobre esta perspectiva metodológica de pesquisa e de ensino a partir da proposição, por exemplo, de EDF desenvolvido em turmas da educação básica com um número maior de alunos.

\section{REFERÊNCIAS}

ALVES-MAZZOTI, A. J.; GEWANDSZNAJDER, F. O método das ciências naturais e sociais: pesquisa quantitativa e qualitativa. São Paulo: Editora Pioneira, 1998. 203p.

AQUINO, O. F. O experimento didático-formativo: contribuições para a pesquisa em didática desenvolvimental. In: Didática e Prática de Ensino na relação com a Formação de Professores. 2014. E-Book. ISBN: 978-85-7826-293-8. Disponível em: http://www.uece.br/endipe2014/ebooks/. Acesso em: maio 2017.

BORTOLETTO, A; CARVALHO, W. L. P. Temas sociocientíficos: análise dos processos argumentativos no contexto escolar. In: CARVALHO, L. M. O.; CARVALHO, W. L. P. Formação de professores e questões sociocientíficas no ensino de ciências. São Paulo: Escrituras Editora, 2012.

CAPELO, A.; PEDROSA, M. A. Formação inicial de professores de ciências, problemas atuais percursos investigativos. In: SANTOS, W. P.; AULER, D. (org.). CTS e educação científica: desafios, tendências e resultados de pesquisa. Brasília: Editora Universidade de Brasília, 2011. p. 439-461.

CONRADO, D. M.; NUNES-NETO, N. (org.). Questões sociocientíficas: fundamentos, propostas de ensino e perspectivas para ações sociopolíticas. Salvador: Edufba, 2018. 570p.

DAVÍDOV, V. V. Problemas do ensino desenvolvimental: a experiência da pesquisa teórica e experimental na psicologia. São Paulo: Atlas, 2003.

DAVÍDOV, V. V. Problemas do ensino desenvolvimental: a experiência da pesquisa teórica e experimental na psicologia. Trad. José Carlos Libâneo e Raquel A. M. da Madeira Freitas. Revista Soviet Education, n. 8, v. XXX, ago. 1988.

DUARTE, N. Formação do indivíduo, consciência e alienação: o ser humano na psicologia de A. N. Leontiev. Cadernos Cedes, v. 24, n. 62, p. 44-63, 2004. Disponível em: http://www.scielo.br/scielo.php?scrip$\mathrm{t}=$ sci_arttext\&pid=S0101-32622004000100004\&lng=en\&nrm=iso. Acesso em: 5 jul. 2019. http://dx.doi. org/10.1590/S0101-32622004000100004.

ENGESTROM, Y. Activity theory and expansive design. Theories and practice of interaction design, p. 3-24, 2006.

LEONTIEV, A. O desenvolvimento do psiquismo. Lisboa: Horizonte, 2004.

LEONTIEV, A.; LURIA, A.; VIGOTSKY, L. S. Psicologia e pedagogia: bases psicológicas da aprendizagem e do desenvolvimento. São Paulo: Moraes, 1991. 
LIBÂNEO, J. C.; FREITAS, R. A. M. Vygotsky, Leontiev e Davydov: contribuições da teoria histórico-cultural para a didática. In: SILVA, Carlos C.; SUANNO, Marilza V. R. Didática e interfaces. Rio de Janeiro: Deescubra, 2007.

LIBÂNEO, J. C.; FREITAS, R. A. M. Vasily Vasilyevich Davydov: a escola e a formação do pensamento teórico-científico. In: LONGAREZI, A. M.; PUENTES, R. V. (org.). Ensino desenvolvimental: vida, pensamento e obra dos principais representantes russos. Uberlândia: Edufu, 2013.

MORAES, R. Uma tempestade de luz: a compreensão possibilitada pela análise textual discursiva. Revista Ciência e Educação, v. 9, n. 2, p. 191-211, 2003.

MOURA, M. O.; SFORNI, M. S. F.; ARAUJO, E. S. Objetivação e apropriação de conhecimentos na atividade orientadora de ensino. Revista Teoria e Prática da Educação, v. 14, n. 1, p. 39-50, 2011.

RATCLIFFE, M.; GRACE, M. Science education for citizenship: teaching socio-scientific issues. Maidenhead: Open University Press, 2003.

SFORNI, M. S. F. Interação entre didática e teoria histórico cultural. Educação e Realidade, v. 40, n. 2, p. 375-397, 2015.

VALE, W. K. M. Um olhar sobre os processos de apropriação e objetivação da abordagem de questões sociocientíficas na formação de professores de ciências naturais. 2017. 155f. Dissertação (Mestrado) Universidade Federal Rural de Pernambuco, 2017.

VALE, W. K. M.; SANTOS, R. C. S.; CUNHA, M. L. Um panorama atual sobre as questões sociocientíficas na formação de professores de ciências. In: COLÓQUIO INTERNACIONAL DE EDUCAÇÃO E CONTEMPORANEIDADE, 10., 2016, p. 1-13.

ZEIDLER, D.; SADLER, T.; SIMMONS, M. L.; HOWES, E. V. Beyond STS: A reseash-basead Framework for Socioscientific Issues Education. Science Education, v. 89, p. 57-77, 2005. 